\title{
4. Theory and practice of cryptography in early modern Europe ${ }^{1}$
}

\subsection{Vulnerable ciphers: the monoalphabetic way}

We would not have to waste a lot of words on the pre-140o history of cryptography if it were not for the Arabs. Most of the cryptographic methods in Latin and later in national languages remained on the level of simple substitutions until the late medieval centuries. In the beginning only vowels were substituted for signs that were made up of dots and then graphic symbols. Later every single letter of the plain text was replaced by a corresponding numeral, letter or symbol. That means that, as the ciphertext was being constructed, the user took the letters from the plain text one by one and wrote their corresponding symbol down in the secret (or rather encrypted) text. ${ }^{2}$ This method assigned one single string of symbols, numerals or letters to the original alphabet, in other words, it used one single code alphabet to encipher the plain text, and therefore this encryption is called the monoalphabetic cipher.

Cum Amorato de Torollis. Jam diu.

$\begin{array}{llllllllllllllllllllllll}\mathrm{a} & \mathrm{b} & \mathrm{c} & \mathrm{d} & \mathrm{e} & \mathrm{f} & \mathrm{g} & \mathrm{h} & \mathrm{i} & \mathrm{k} & \mathrm{l} & \mathrm{m} & \mathrm{n} & \mathrm{o} & \mathrm{p} & \mathrm{q} & \mathrm{r} & \mathrm{s} & \mathrm{t} & \mathrm{u} & \mathbf{x} & \mathrm{y} & \mathrm{z} \\ \mathrm{c} & \mathrm{y} & \mathrm{x} & \mathrm{u} & \mathrm{t} & \mathrm{s} & \mathrm{r} & \mathrm{q} & \mathrm{p} & \mathrm{o} & \mathrm{n} & \mathbf{1} & \boldsymbol{2} & \mathbf{3} & \mathbf{4} & \mathbf{5} & \boldsymbol{b} & \mathbf{7} & \mathbf{8} & \mathbf{9} & \mathrm{T} & \mathbf{7} & \mathrm{k}\end{array}$

Monoalphabetic cipher from Mantua $(1395)^{3}$.

Monoalphabetic ciphers are rather vulnerable. It may seem at first that in the case of a 22-letter alphabet, the codebreaker must choose from 22! (twenty-two factorial), that is $22 \times 21 \times 20 \ldots \times 3 \times 2 \times 1=1124000000000000$ ooo ooo possibilities, which is a highly time-consuming task, almost impossible without the help of a computer. Fortunately, the life of the codebreaker is not this difficult. There is a range of mathematical methods

1 This chapter is the elaboration and amplification of the 6th chapter of my Rohonc Code.

2 Medieval methods are classified in helpful categories in Bernhard Bischoff, "Übersicht über die nichtdiplomatischen Geheimschriften des Mittelalters" Mitteilungen des Instituts fur Österreichische Geschichtsforschung 62 (1954): 1-27, see also: Kahn, The Codebreakers; Meister, Die Anfänge der modernen diplomatischen Geheimschrift, idem, Die Geheimschrift im dienste der päpstlichen Kurie.

3 Meister, Die Anfänge der modernen diplomatischen Geheimschrift, 41. 
available with which one can radically narrow down the number of possibilities to break this type of cipher. The best-known method of this kind is frequency analysis. This is quite a down-to-earth method in which the codebreaker counts each character of the ciphertext and tries to match the most frequent ones to the most frequent letters of the supposed language of the plain text. The reliability of this method is based on the fact that languages are strongly characterized by the frequency of their letters, a feature that is rather constant in every text written in the given language. All of this is only true, of course, if the encryption did not substitute all the vowels with 'e' for example, did not intentionally make spelling mistakes, and did not use a technical terminology. Military jargon, for example, uses a smaller number of articles.

In present English the letters E T A O I N S H R D L U are the most frequent, in this order, with $\mathrm{Z}$ being the least common. In French these are E N A S R I U T O L D C, in German, E N R I S T U D A H G L, in Italian, E I A O R L N T S C D P, in Spanish, E A O S R I N L D C T U, while the Hungarian table of frequency starts with the letters E A T L N. The relative frequency table of any language can be easily created by counting all the letters of half a page of text, or even more simply, by downloading a readymade graph from the Internet.

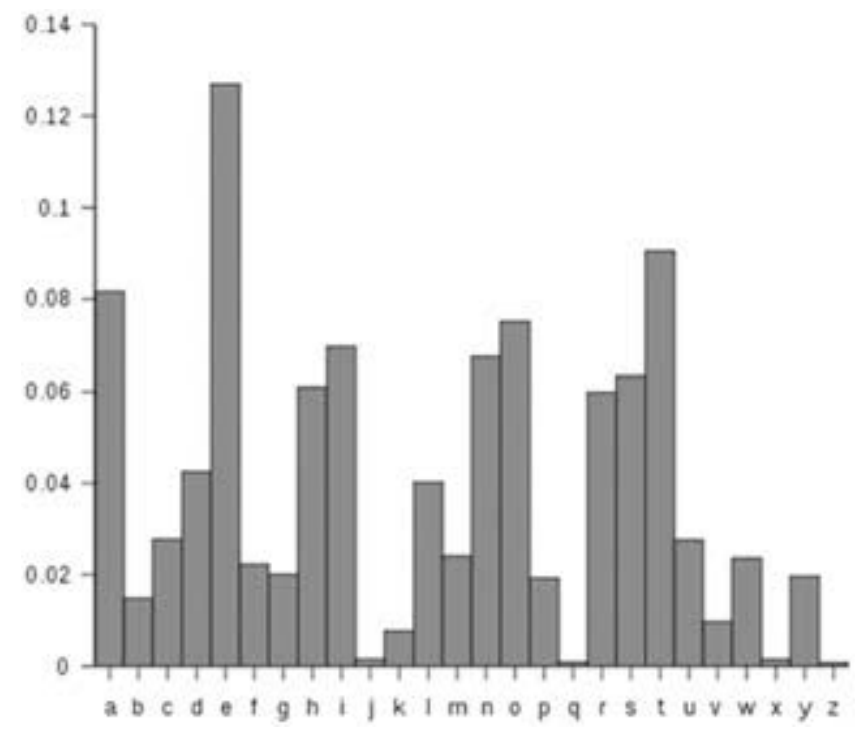

The characteristic frequency of letters in the English language Source:Wikipedia http://en.wikipedia.org/wiki/Frequency_analysis 
Since in the monoalphabetic cipher identical codegroups are substituted for identical letters repeating the pattern of the plain text in the ciphertext, and different codegroups stand for different characters, it takes only a few attempts to match the tallest columns in the frequency chart of the original language to the similarly tall columns in the frequency chart of the language of the coded text. The longer the secret writing available to us is, the more precisely it can be fitted to the frequency chart of the original language - most often a half-page sample is enough for this operation. This assigning process, of course, almost never works automatically, it takes several attempts to successfully match the string of the most frequent characters to the string of the most frequent letters.

Besides the frequency of letters, advanced codebreakers also analyze the frequency of bigrams (a sequence of two letters), trigrams (a sequence of three letters) and digraphs (a pair of letters used to write one speech sound). The most frequent bigram in the English language is $\mathrm{TH}$, the most frequent trigram, not surprisingly, is THE. The most frequent digraphs are SS, EE and TT. In light of this kind of linguistic statistical data, the monoalphabetic cipher cannot be considered secure.

Though the methods described above make the job of the codebreaker a lot easier, in reality many people use simpler (so-called brute force) ways to decipher monoalphabetic secret writings: they look for a prominent pattern in the flow of characters and assign it to the most frequent syllables of the supposed language of the plain text. An excellent example of this is the Cipher Challenge of Simon Singh that he published in the original edition of his book on the history of secret writings, The Code Book. Singh offered valuable prize money for the deciphering of ten coded messages. Having worked together for one year, a group of amateurs and professionals coming from all over the world finally solved the Challenge in October 200o. They published their codebreaking methodology, so we know from first hand that instead of applying difficult computer-assisted algorithmic methods, they used pen and paper and brute force to decode the first few (simplest) tasks of the challenge. ${ }^{4}$

Now that we learned how easy it is to solve monoalphabetic ciphers in theory either by frequency analysis or by brute force, it should be emphasized that with historic ciphers this optimism is rather unfounded. The method of simply looking at a text and recognizing its linguistic structures immediately obviously depends on whether word boundaries are indicated in the code text, whether the original language is known, whether this 
language is well known and whether the scribe had used consistent spelling. In case there are no word boundaries and the codebreaker is uncertain about the language, they are not likely to be successful with the 'take a glance at' technique. It is in such instances that letter-frequency methods should be applied. A seventeenth-century Hungarian text, nonetheless, may prove to be quite a challenge even for proper statistical methods. One may be disappointed if they expect the same character not to stand three times in succession within the same word on the grounds that there are no Hungarian words with the same letter repeated three times. As a matter of fact, scribed often made mistakes, they left out characters or accidentally noted a code number twice. One may be disappointed if one expects a coherent spelling - nothing was further from the scribe than the wish to conform to our modern-day expectations about spelling coherency. It is not obvious, for example, whether he had spelled the Hungarian word 'hogy' (meaning: that) as 'hogy' or as 'hogi'. It is not evident if he had used different signs for the accented vowels (and there are many such vowels in Hungarian!), if he had used a simplified alphabet containing no accents, or whether he had a mixed approach. One cannot be sure if he had a distinct $v$ and $u$ letters or if he had used the same sign for both. Whether he had a distinct $i$ and $j$ letters or if he had used the same sign for both.

Knowing the relative frequency of letters in today's Hungarian does not help, and neither does creating our own frequency charts based on the old texts published - according to the publishing conventions of the day - in a more or less modernized way. One may, of course, use a letter-perfect transcript of a manuscript for this purpose. It has to be decided in this case, however, whether the accented vowels should be taken into consideration in creating the frequency charts, or whether the letters $u$ and $v$, and $i$ and $j$ should be considered as two or as one character. In case the codebreaker is not sure whether the text is Hungarian, German, Latin or French, the problems are multiplied. For now, let it be enough to remark that even though a seventeenth-century letter had been encrypted by a monoalphabetic method without knowing the word boundaries, the base language and without trusting that a coherent spelling was used - the historian may not be successful with the frequency analysis or with any other statistical methods, they will also be required to apply historical and linguistic considerations. This is why the difficulties created by some letters encrypted in the monoalphabetic waywhich survived, as we will see later, in surprisingly high numbers from the early modern period of Hungarian history - should not be belittled.

After this detour into modern day deciphering problems, let us now redirect our attention to the people of the past. They faced fewer obstacles 
because they usually knew the original language of a coded message, just as they were thoroughly familiar with the language of their time (and not confused by a modernized and unified language form that is only to come centuries later). This is why we should not be surprised that although the contemporaries of Julius Caesar, Charlemagne, medieval papacy and the North-Italian city-states apparently did use monoalphabetic ciphers but not frequency analysis, most of the time they did not entrust their diplomatic secrets to this unreliable tool. The vulnerability of the messages was further enhanced by the fact that a great percentage of pre-fifteenthcentury letters was only partially enciphered. Sometimes only vowels were coded, and sometimes letters of the plain text were simply substituted by the following letter of the same alphabet (writing $b$ instead of $a, c$ instead of $b$ ). Dozens of ciphered letters as well as numerous cipher keys survived from before 1400; most of the time, however, non-cryptographic methods were preferred to hide important messages. Letters were, for example, simply hidden in the clothes of the messenger.

\subsection{An Arabic contribution: the cryptanalysis}

In the Western world, the birth of the science of cryptography in the strictest sense did not take place until the fifteenth century, when the simple monoalphabetic substitution method was started to be replaced by new strategies. This only happened around 1400 despite the fact that medieval Arab scientists had already achieved significant results. Beginning from the twelfth century, Western culture already owed a great deal to Arab science in several other fields. They became familiar with the achievements of the Arab world, the fundamental texts of which were being assiduously translated. The Arabs were equally fruitful in the fields of astronomy, mathematics, optics, logic, philosophy, alchemy, astrology and practical magic. Their texts were read and translated into Latin by dozens of translators. In the course of the reception, these translations had to be examined from the perspective of Christian theology: it had to be decided what to adopt from the science of Aristotle, Galen, Ptolemy and the Arabs and what to reject. This reception, which was initially characterized by enthusiasm more than depth, but then it was gradually replaced by careful analyses, recognized and reacted to the scientific superiority of the Arabs. ${ }^{5}$

5 Marie Thérèse d'Alverny, La transmission des textes philosophiques et scientifiques au Moyen Age, ed. Charles Burnett (Aldershot: Variorum, 1994); Charles Burnett, Magic and Divination in 
This recognition and reaction did not characterize the reception of cryptography, although Arab writers described precisely how to decipher monoalphabetic ciphers with methods based on language statistics and were already designing newer and better encrypting methods. We have only recently recognized the real impetus of the achievements of the Arabs, more precisely since historians have started publishing the Arabic Origins of Cryptology, a series containing the most crucial documents: sources that were found in the manuscript collections of Istanbul. ${ }^{6}$ In light of these we can argue that cryptology, by origin, is a truly Arabic discipline. In other areas of science, such as mathematics, philosophy and logic, the Arabs might have acted as mere transmitters (though decisive ones), but the science of cryptography was not taken over from the Greeks or the Romans to be developed further - it was created by the Arabs from almost nothing. To be sure, there had been simple encrypting methods in the ancient Greek and Roman world too, but it was the Arab writers who attempted for the first time to systematize the methods of decrypting ciphers. This is how the actual science of cryptology was born, covering both cryptography (secret writings) and cryptanalysis (code-breaking).

Editors of the texts of Arabic cryptology explain its birth with four mutually influential reasons, two of these related to the development of linguistics. To begin with, the Arabic culture had made serious efforts to translate into Arabic such texts that had been written in other, often somewhat obscure, languages. Secondly, the Arabic language was itself an object of meticulous study that sometimes even applied statistical methods. The third reason lies in the well-known advancement of Arabic mathematics, hence the very common sifr stem (meaning number in Arabic) in many a cryptological term (e.g. chiffre). Note how Arabic numerals were necessary for doing efficient language statistics, being more suitable for mathematical manipulations than the traditional Roman numerals. Finally, the fourth reason behind the advancement of cryptology could be the growth of administration in the rapidly expanding Arab states. The editors

the Middle Ages: Texts and Techniques in the Islamic and Christian Worlds (Aldershot: Variorum, 1996); David Pingree, "The Diffusion of Arabic Magical Texts in Western Europe," in La diffusione delle scienze Islamiche nel Medio Evo Europeo, ed. B. Scarcia Amoretti, 57-102 (Rome: Accademia Nazionale dei Lincei, 1987).

6 The series publuished by KFCRIS \& KACST and edited by Mohamad Mrayati, Yahya Meer Alam, and M.Hassan at-Tayyan, has thus far six volumes: al-Kindi's Treatise on Cryptanalysis (2003); ibn Adlan's Treatise (2003); ibn ad-Durayhim's Treatise (2004); ibn Dunaynir's Book (2005); Three Treatises on Cryptanalysis of Poetry (2006); Two Treatises on Cryptanalysis (2007). 
cite important writers from all four major areas that support the claim that these fields were explicitly interrelated, often with the same authors active in them. ${ }^{7}$

The first of these, a scholar from Baghdad, also prominent in the fields of philosophy, geometry, optics, etc. was Ya'qūb ibn Ishāq Al-Kindi (8o1?-873?). As early as twelve hundred years ago, Al-Kindi was already familiar with the letter-frequency analysis for solving ciphers. This means that in the ninth century he could easily have broken the kind of monoalphabetic codes that the Western world used as late as in the fourteenth century in diplomacy. During the next half millennium, Arab cryptology flourished in the life and works of scholars, poets and linguists from Damascus and Cairo, as seen from the handbooks of ibn 'Adlan, (1187-1268), ibn Dunajnir (1187-1216), ibn ad-Durajhim (1312-1359), al-Qualquashandi $\left(1355^{-1418)}\right.$ and others. ${ }^{8}$ The majority of the ciphers described by these authors, however, remains basically monoalphabetic. For example, they suggest assigning letters of a different language (Hebrew, Greek, Mongolian, Armenian, Persian, etc.) to the letters of the Arabic alphabet so the text is written in Arabic, but with foreign characters. Alternatively, they point out, one could even make up one's own imaginary system of characters. Al-Kindi introduces a method in which sometimes one, and sometimes two letters of the plain text are substituted with one ciphertext character. al-Qualquashandi mentions a procedure where two Arabic letters of the ciphertext correspond to one letter of the plain text in a way that the numerical values of the two letters equal the numerical value of the substituted character (note that each letter of the Arabic alphabet has a numerical value). ${ }^{9}$ Moreover, at least three hundred years before the idea of a homophonic cipher first occurred to the Westerners, an anonymous writer's handbook from the tenth-eleventh centuries entertained the possibility of assigning several code characters to the more frequent letters of the plain text. ${ }^{10}$ These methods considerably go beyond simple monoalphabetic substitutions, and might efficiently resist frequency analysis.

7 Mohammed Mrayati, Yahya Meer Alam, M. Hassan at-Tayyan, eds. al-Kindi's Treatise on Cryptanalysis (The Arabic Origins of Cryptology, 1), (Riyadh: KFCRIS, 2003), 44-74.

8 Besides the publications above, see also: Ibrahim A. Al-Kadi, "Origins of cryptology: The Arab contributions," Cryptologia, 16 (1992): 97-126.

9 Abdelmalek Azizi and Mostafa Azizi, "Instances of Arabic Cryptography in Morocco," Cryptologia 35 (2011): 47-57.

10 Mohammed Mrayati, Yahya Meer Alam, M. Hassan at-Tayyan, eds. Two Treatises on Cryptanalysis, 25 . 
Discussion of the code-breaking methods, that is, cryptanalysis, is even more important in the Arabic handbooks than these sophisticated encrypting methods. Cryptanalysis starts with the careful study of the plain text's language: the frequency of letters, letter pairs, letter combinations, and an analysis of the typical word patterns. The authors suggest examining which letters stand together regularly, and which ones never stand next to each other; which letters stand typically at the beginning of words and which never; which ones are usually doubled in an average Arabic text. As for the cipher text, they recommend counting the characters in order to identify the language, identifying which characters could signal word boundaries, as well as trying the method of probable word break. This last technique, which was not applied in the West until the sixteenth century, means taking a word that we suspect to be contained by the ciphertext, and simply try it on the cryptogram looking for a string of signs with a similar structure.

These methods constitute and impressing early advance in the science of cryptanalysis, however, since the time of Al-Kindi the frequency analysis was considered to be the main tool: Al-Kindi, ibn 'Adlan and the others produced ample statistics on the relative frequency of the letters and letter combinations of the Arabic alphabet.

\subsection{New methods in the literature: the polyalphabetic cipher}

Despite the fact that through these achievements the Arabic legacy became far more advanced in this field by the fourteenth century, there is no sign that they became either a source of inspiration, or a powerful opponent for Western cryptography for the coming centuries. As if the treatises discussed above had hidden in the archives of Istanbul, to sit quietly, waiting till the end of the twentieth century to be discovered. Apparently, Western cryptography took off unaware of the achievements of the Arabs, partly due to a number of theoretical studies, partly to the practicing cryptologists of various Italian diplomatic services. As for the theory, it was the leading scholars of the age who authored the monographs on cryptography too. ${ }^{11}$ If we look into the books of Leon Battista Alberti, ${ }^{12}$ Johannes Trithemius, ${ }^{13}$

11 Kahn, The Codebreakers, 106-188.

12 Leon Battista Alberti, "De Componendis Cyfris," in Meister, Die Geheimschrift, 125-141, idem; A Treatise on Ciphers (Torino: Galimberti, 1997.)

13 Johannes Trithemius, Polygraphiae libri sex (Oppenheim: Haselberg de Aia, 1518), Steganographia: ars per occultam scripturam (Frankfurt: Becker, 16o6) 
Giambattista Della Porta, ${ }^{14}$ Gustavus Selenus, ${ }^{15}$ Blaise Vigenère, ${ }^{16}$ or the English John Falconer ${ }^{17}$ we are at first astounded to find the great array of methods available to early modern users.

Some of these were elementary operations based on monoalphabetic substitution, or on transposition (mixing up the letters of the plain text), ciphers that could easily be broken by frequency analysis, by a vowelidentifying algorithm, or by any other paper-to-pen method. These writers, the first of whom is the reputable fifteenth-century architect, Leon Battista Alberti (1404-1472), nevertheless, describe more complex polyalphabetic ciphers too. In these the consecutive letters of the plain text are replaced by characters that are selected from several different code alphabets. In other words, letters of the plain text are not replaced by letters from one single code alphabet, but several ones. As we encode each letter we regularly switch the code alphabets, according to a certain, easy-to-follow system. Initially, Alberti's method was to switch alphabets only after every few words, but more frequent changing of the alphabets is also possible. Alberti's famous disk helps us understand the procedure.

There are twenty uppercase letters and four numerals in the outer ring, for the plain text. The letters A J, K, Y and $\mathrm{H}$ are not represented, partly for the sake of simplicity, partly because of the way the system is operated. The rotatable inner ring displays the lower-case letters of the cipher alphabet in a mixed order. When we start working with the plain text, we fix the inner ring and write down the lower-case letter that is opposite B. Then we start encryption, and do not rotate the ring until we do not wish to change code alphabets. If we do, however, we insert one of the four numerals 1, 2, 3 or 4 in the plain text, and the letter corresponding to these in the ciphertext. Then we rotate the rings so this lower-case letter is opposite B, and continue the process until we decide to change the code alphabet again. The strength of the method lies in the fact that the code alphabet is mixed, and the way it is changed is unpredictable and arbitrary.

14 Giambattista Della Porta, De furtivis literarum notis vulgo de ziferis liber quinque (Naples: Johannes Baptista, 1602), De occultis literarum notis, seu artis animi sensa occulte aliis significandi (Starssbourg: Zetzner, 1606).

15 Gerhard Strasser, "The Noblest Cryptologist: Duke August the Younger of Brunswick-Luneburg (Gustavus Selenus) and His Cryptological Activities" Cryptologia 7 (1983): 193-217; idem, "Die kryptographische Sammlung Herzog Augusts: Vom Quellenmaterial für seine Cryptomenytices zu einem Schwerpunkt in seiner Bibliothek" Wolfenbütteler Beiträge 5 (1982): 83-121.

16 Blaise de Vigenère, Traicte des Chiffres (Paris: Abel l'Angelier, 1586).

17 J. Falconer, Rules for explaining and deciphering all manner of secret writing (London: Printed for Dan. Brown and Sam. Manship, 1692). 


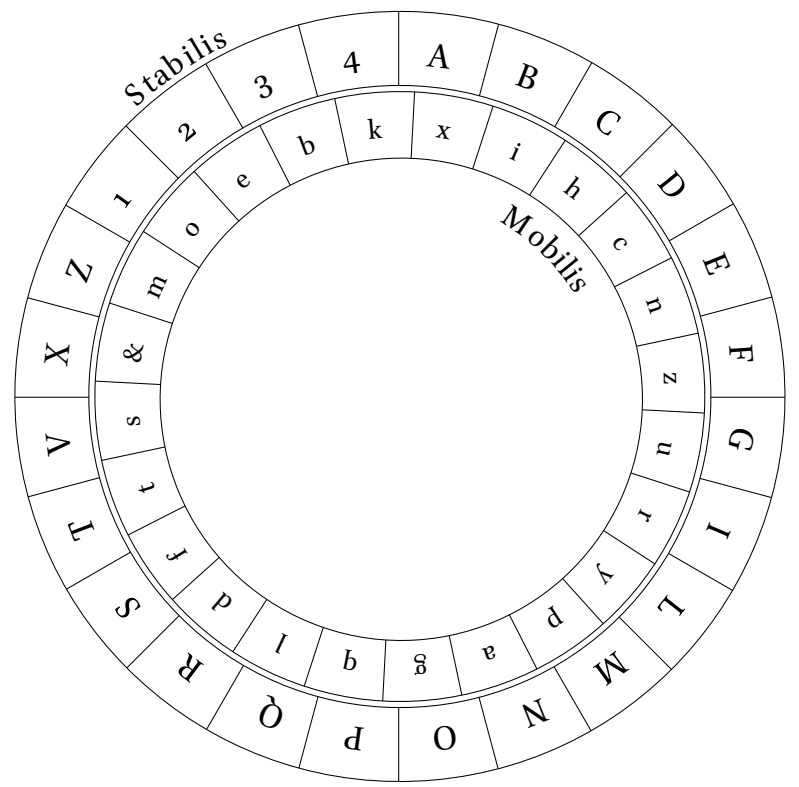

Alberti, De Componendis Cyfris, 1446

This polyalphabetic method was further developed by Trithemius, J. B. Bellaso, Della Porta and later Vigenère. It was Trithemius who introduced the polyalphabetic table (a list of alphabets), in which he looked up the first letter of the plain text in the first row of the table, and encrypted the following letters of the plain text according to the corresponding letters in the following alphabets.

Vigenère added a twist to the use of this table. We take a code word (in honor of the inventor let it be alberti) and we encrypt the consecutive letters of the plain text according to the alphabets starting with the letters of the word alberti. We look up the equivalent for the first letter in the row starting with the letter $a$, the second letter in the row starting with the letter $l$, and so on, till the seventh letter in the row starting with the letter $i$, and then we start again: the eighth letter is looked up in the row starting with the letter $a$. This is the way we go through the letters of the word alberti again and again, until we are finished with the process. The main strength of this method compared to monoalphabetic, or even homophonic systems is that it significantly raises the level of entropy in the text.

But what is entropy, and why does it need to be increased? Simply put, entropy is the measure of disorder. Mathematicians use this and similar ways to define the entropy of $\mathrm{X}$ : 


$$
H(X)=\sum_{i=1}^{n} p_{i} \log _{2}\left(\frac{1}{p_{i}}\right)
$$

We could start out from this equation too, but let us use another, more expressive example to explain the idea of entropy. Every text written in a natural language shows strong patterns. In Latin and Neo-Latin languages, for example, the letter $q$ is always followed by the letter $u$, and $h$ often comes after $t$ in English, but rarely the other way around. In Hungarian, the sequence $a z$ (the definite article: 'the') and hogy (meaning 'that') are very frequent, but $z a, o g y h$ and gyoh are less common, and most likely the hgyo sequence never occurs naturally. In English, the occurs in high numbers, but not eth, in Latin que is very common, but euq, uqe do not exist, and equ can hardly ever be found. In every language, the number of existing letter combinations is relatively restricted compared to the number of all such possible combinations. The stronger the structure, the higher the order in a given language, and entropy (or disorder) is smaller. Higher order, nevertheless, means higher predictability of the words of a given language, that is why smart phone software so successfully predicts the continuation of the words we are writing. The more predictable a system, the less secret it is, the easier it becomes to decipher. Once part of the text is decoded, the rest becomes easier to guess.

Monoalphabetic ciphers do replace every letter of the plain text, but the ciphertext will display the same patterns as the original text. Should the combination 22-17-46 occur in a relatively high number in an originally English ciphertext, we are right to suppose that this sequence stands for the letters of the article the. The polyalphabetic cipher, in contrast, mixes up the characteristic patterns of the base language, concealing the typical structures of the plain text and raising the level of entropy (or disorder). Each the word in an English text will look different, for these three letters will be enciphered according to three different alphabets each time.

Note, however, that in classic polyalphabetic methods the code alphabets are used in the same strict order. With a sample long enough, we are likely to find a pattern in the plain text (two the words, for example, that are coded in the same way, using the same succession of three code alphabets). The weak point of the system is, therefore, periodicity, the fact that the code alphabets are used in the same order. Using this feature, it becomes possible to break a ciphertext - an idea that was served as the base of the ingenious method of Charles Babbage (1791-1871) and Friedrich Kasiski (1805-1881), who finally broke the polyalphabetic 
cipher. ${ }^{18}$ However complex, developed and twisted the upgraded polyall phabetic system of Vigenère may seem, certain writers, like Sacco, plausibly argue that it is actually a step back compared to the less predictable system of Alberti. ${ }^{19}$ Code alphabets were ordered, their selection was pee riodic, and the code word was often a meaningful, existing word, making this algorithm predictable and breakable. This was not to be recognized until much later. During the period we are now examining, however, it was regarded very powerful, and the idea that it could be broken did not even emerge until the nineteenth century.

A special case of polyalphabetic ciphers is Ádám Pálóczi Horváth's secret writing mentioned above, which was deciphered by Hanna Vámos. The first letter of each word was left unchanged, the second was substituted by the letter following it in the alphabet, the third letter by the second letter that stands after it in the alphabet, and so on. Instead of $e t$, we write $e u$, instead of purissimo, pxtmyzpty. Although this is undeniably a polyalphabetic cipher, where each letter of a given word is enciphered by a different code alphabet, it is apparent that the plain text does not become disorganized enough, leaving strong structures in the code text. A simple shifting of the alphabet by one (encoding each letter by an alphabet that is the neighbor of the previously used alphabet), and the fact that this shifting cycle starts again with the beginning of every word makes this code vulnerable. This certainly does not lessen the merit of the codebreaker who recognized this pattern in the seemingly jumbled-up text. ${ }^{2 \circ}$

Let us now return to the major cipher handbooks from the sixteenth century. Beside encryption methods in the strictest sense, the works of Trithemius, Della Porta, Vigenère, Selenus, and Falconer also discuss a number of techniques for actually hiding messages, not so much connected to the area of cryptography, as to that of steganography (the art of concealing messages). One example is when only certain letters of a seemingly intelligible, but unimportant text should be read, the rest should be left out. Gustavus Selenus discusses such methods in great length, including those in which only the first letter of each word should be considered as relevant elements of a message, or only every second 
word-starting letter. ${ }^{21}$ Similarly popular are the syllable methods in these monographs. These assign a text character to a plain text syllable, or double characters to letter pairs, and so on.

\subsection{Practice in diplomacy: the homophonic cipher}

This rich diversity in the theory did not result in a similar variety in the practice. In sharp contrast with the sophistication exposed in the handbooks, the majority of the considerable cipher methods that were actually used (besides the old monoalphabetic procedure) in the fifteenth to seventeenth centuries fall under the same subcategory of a single method, and one that is hardly mentioned in the handbooks above: the homophonic cipher. $^{22}$

The homophonic cipher was formed gradually during the late fourteenth-century practice of Italian diplomacy. Official cryptography appeared in the decades following 1395 in the chancellery of the Pope as well as in Venice, Florence and a number of other Italian towns. The sporadically used methods based on vowel substitution slowly merged into code alphabets where each letter was replaced by a letter, number, or a graphic sign, and then, step-by-step, second or third signs (homophones) were added to these monoalphabetic alphabets to replace the most common vowels. Meanwhile, another coding tradition was channeled into the practice, which applied a so-called nomenclature, a list of code signs for the most common words, political figures and geographic names. Around 1400, these code signs were inserted into the cipher keys so that the regular names and expressions do not stand out from the ciphertext. Finally, nullities, signs without meaning, were more regularly employed. As a consequence of these improvements, it has become problematic for the codebreaker to figure out if a character stands for a letter, a political figure, or nothing. ${ }^{23}$ Hoo mophonic ciphers were born practically from the realization that through

21 Selenus, Cryptomenytices, Book 3.

22 About the gap between the theory and practice of early modern cryptography, see: Kahn, Codebreakers, 156. for different approaches to the same issue: see Strasser, Lingua Universalis, 249; and de Leeuw, "Cryptology in the Dutch Republic: a case-study" in idem and Jan Bergstra, eds. The History of Information Security: A Comprehensive Handbook. Amsterdam: Elsevier, 2007: 324-364, particularly: 329-330.

23 Meister, Die Geheimschrift, 21-23, 171-176, idem, Die Anfänge, 14-15. 
frequency analysis, the monoalphabetic methods had become rather fragile. The first complete code keys of this type containing a full code alphabet, homophones for the vowels, a list of nomenclatures and nullities all in one, first appeared in 1411 in Venice, then in 1412 in the papal court, and in 1414 in Florence.

The more important Italian political centers soon employed their own codebreaker who occasionally also wrote a treatise on cryptology. Some of them are well-known: Gabriel de Lavinde served in the court of antipope Clement VII, Antoine Elio worked first in the court of Paul III, then of Paul IV; and the Argentis: Giovanni Battista Argenti, and his nephew, Matteo were the codebreakers of Sixtus V and Gregory XIV, popes in the late sixteenth century. A good indicator of the prestige surrounding codebreaking is the fact that members of this profession were highly regarded, they worked separated from scribes doing the simple, mechanic part of enciphering, and assistants were often assigned to help their activity. Both in the papal court and in the Republic of Venice this field was institutionalized around 1540 to the extent that they opened an official codebreaking office. In Venice, the codebreakers' room was directly in the Doge's Palace, above the Secret Chamber. They were not to be disturbed in their work, and legend has it that they could not leave their room until they had broken the incoming ciphers.

The homophonic cipher thus became the dominant method of the late medieval and early modern times. It was simple, easy-to-follow and practical, and one only needed one or two pages of the cipher table. These tables - in their mature form - consisted of the following five categories.

1) Three or four different characters, that is, homophones assigned to each letter of the alphabet. More common letters are usually assigned more characters than the less common ones. The role of homophones is to make frequency analysis unhelpful, and also to hide characteristic word structures in order to hinder probable word break.

2) Special characters for the most common double letters. This category was not yet included in the earliest homophonic keys, but became more common during the fifteenth century, and grew an inevitable part of the sophisticated systems in the sixteenth century. Every language has its special set of double letters, therefore concealing them with one character is an important means to slow down the process of code-breaking. 
3) Special characters for syllables. This method, which also became widespread by the sixteenth century, makes decoding practically impossible. However, the price of this increased security is longer encoding and decoding times, which seemed too big a sacrifice in wartime situations, and thus syllable-substituting characters were often abandoned.

4) Nullities, i. e. characters that do not carry meaning. They confuse a codebreaker, unless a less careful scribe only applied them at the beginning and at the end of a row, which was sometimes the case.

5) Finally, the table of nomenclature, the list of those code words that stand for the most common conjunctions and prepositions, geographical names and political actors. Since these are given a special sign or number (and they are not spelled letter by letter), the system is more likely to resist the "probable word break method", which looks for a word that is most probably found in a plain text, and tries to find its characteristic pattern in the ciphertext.

If one takes two or three homophones for each letter, that makes up an alphabet of approximately one hundred characters. There are usually no more than ten nullities, and the same number of letter pairs. Characters standing for syllables usually number between 100 and 15 o, while a dictionary of code words could contain 300 items or more (although a very high number of code words makes ciphering very impractical). All this could fit on one big or two smaller pages. This method was followed in the early modern diplomatic correspondence of Italy, ${ }^{24}$ Spain, ${ }^{25}$ France,${ }^{26}$ Germany ${ }^{27}$ and Hungary. ${ }^{28}$

24 Meister, Die Geheimschrift; idem, Die Anfänge der modernen diplomatischen Geheimschrift; Karttunen, "Chiffres diplomatiques”; Pasini, "Delle scritture in cifra”; Gaetano Platania, "La Polonia nelle carte del cardinale Carlo Barberieni Protettore del regno," Accademie e Biblioteche d'Italia 56 (n. s. 39) (1988) n. 2. 38-6o; Cecchetti, "Le scritture occulte."

25 Devos, Les chiffres de Philippe II; Biaudet, "Un chiffre diplomatique"; Speziali, "Aspects de la cryptographie."

26 Devos, Seligman, L'Art de Deschiffrer.

27 Rockinger: “Über eine bayerische Sammlung," Stix, "Die Geheimschriftenschlüssel”.

28 Tusor, "Pázmány bíboros olasz rejtjelkulcsa”; Révay, Titkosírások. 


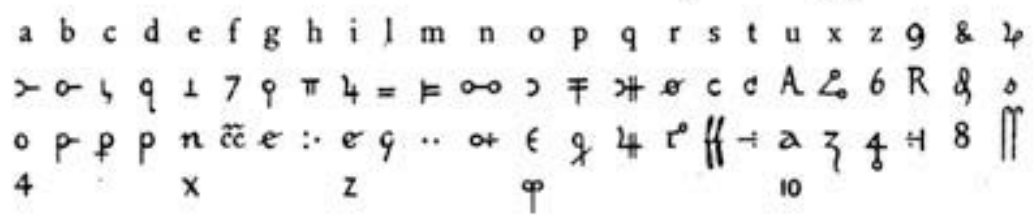

Gemme: $b b \quad c c$ dd $f f$ gg $m m$ nn $p p$ rr ss tt

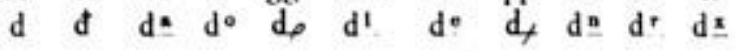

Nihil importantes: \# b-

Quicquid positum fuerit inter hec signa E 7 nihil importabit.

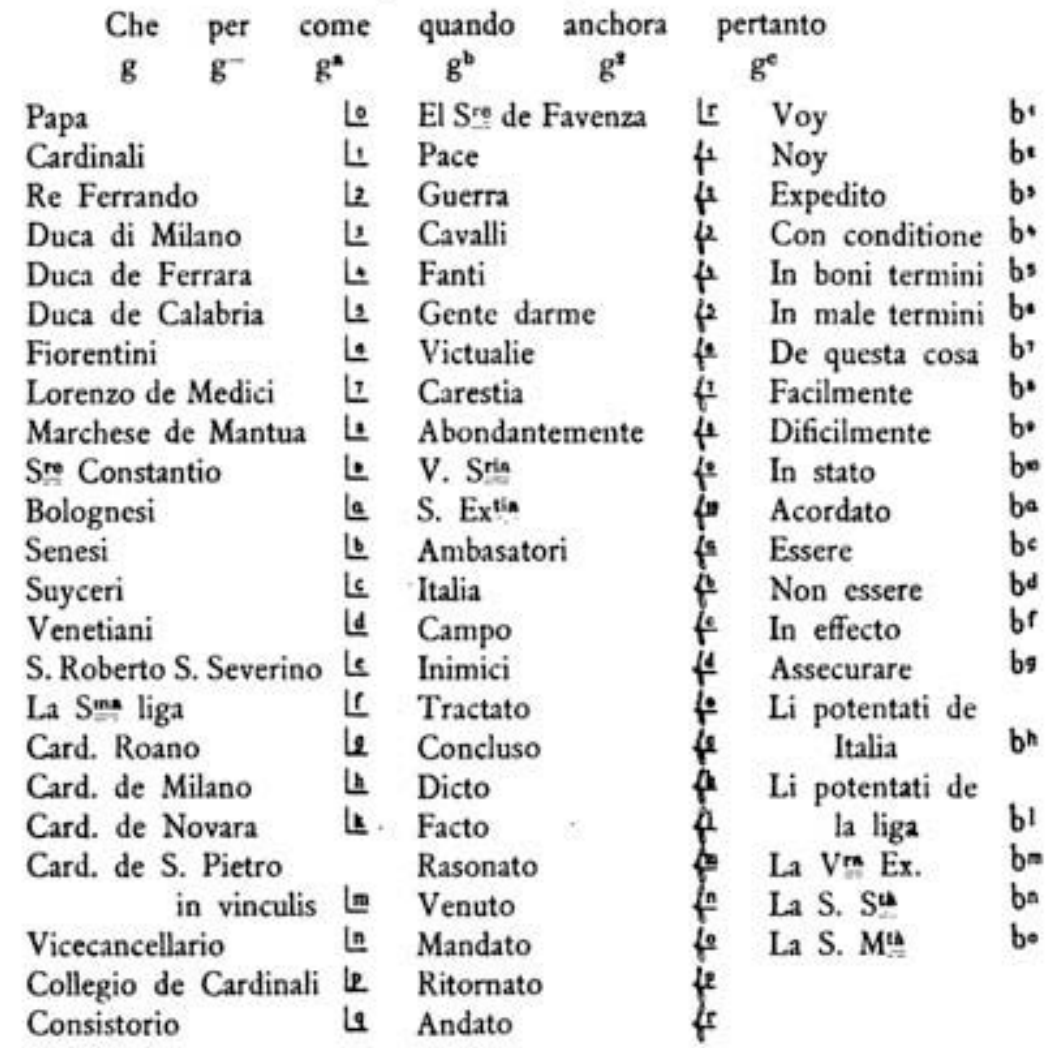

Homophonic cipher in 1483 in Milan. It contains first the homophones, then the characters standing for double letters, than the nullities, some conjunctions, and finally the code words in a nomenclator table. ${ }^{29}$

29 Meister, Die Anfänge der modernen diplomatischen Geheimschrift, 31. 
It should be noted that homophonic tables embody two different cipher methods. Signs assigned to letters and syllables, in other words, units that do not carry meaning but which make up a word fall in the category of cryptography. Statistical analysis and mathematical methods are needed to break them. Nomenclatures, however, are strictly speaking not units of a cipher, they are code signs. These units carry their own meaning regardless of the structure of the given word. Nomenclature tables are in fact dictionaries which assign complete words and ideas to foreign words, or, in our case, code signs. Not so much mathematical analysis is needed to break this code, they should be rather approached as an old language that nobody speaks any more. Breaking a code requires a great deal more encoded texts than breaking a cipher. A further difference is that solution of a cipher composed of letters and syllables can ideally be complete, whereas broken codes often remain partly unsolved - even if the codebreaking was successful, the meaning of some code units might be left unidentified. All in all: the strength of the homophonic cipher comes from a fortunate combination of the advantages of the two kinds of encrypting: ciphers and codes.

Beside the popular homophonic keys, another type of cipher table was in use, although on a much smaller scale, and almost exclusively in the practice of the Papal diplomacy. ${ }^{30}$ Instead of assigning several signs to each letter, the so-called polyphonic cipher assigns the same sign to two or sometimes three letters of the alphabet of the plain text. As seen in the first table below, the numeral 4 can equally stand for the letters $a$ and $m$, or, in the second example, the numeral 9 can stand both for the letters $a$ and $s$. While there are thirty to one hundred homophones in the alphabet of an average homophonic system, the polyphonic method only operates with nine to ten signs, that is, the cipher alphabet is shorter than the alphabet of the plain text. How can such a system function successfully and what are its advantages? The major advantage is that it effectively nullifies frequency analysis, but not because it has assigned more signs to the most frequent letters, but because it has assigned fewer. Deciphering the ciphertext is not that difficult, though undoubtedly lengthy. The addressee writes in several rows the open alphabet letters taken from the code table under the lines of the enciphered text, then, using his linguistic ingenuity and contextual knowledge, composes a meaningful text, selecting in each case from the two or three options. Though ingenious, this method never really became widespread. Mostly it were the secretaries of the Papal office who used it, and only around the mid-sixteenth century. 
Cifra con il Sig. Cosmo Furtado Falcornio in Portogallo.

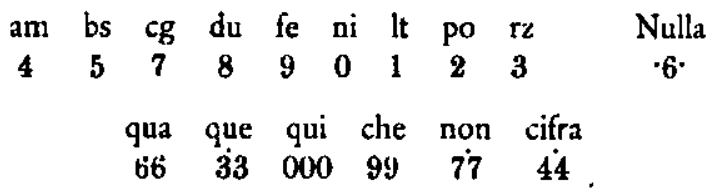

Polyphonic cipher from the papal court from around 1584, from the collection of Matteo Argenti ${ }^{31}$

Con il Toletani.

as bd ce fi gl mn np ro tx Nulle

$\begin{array}{lllllllllll}9 & 7 & 5 & 4 & 2 & 1 & 3 & 6 & 8 & & 8 \dot{9} .3 \dot{3}\end{array}$

$\begin{array}{lllllr}\text { Il Signor lacopo B. } 4 \dot{4} & \text { Il Duca di } & \text { 8̇ } & \text { Il Re di } & 44 \\ \text { Il Papa } & 3 \dot{7} & \text { Il Cardinal di } & 8 \dot{8} & \text { Il Padre } & 999\end{array}$

Polyphonic cipher from the papal court from 1580, from the collection of Matteo Argenti ${ }^{32}$

The homophonic method prevailed until the end of the seventeenth century in both military and diplomatic correspondence. Progress within the system was due to the appearance of syllable codes, on the one hand, and the fact that the nomenclature or code dictionary was becoming longer and longer. By the time of Louis XIV, nomenclatures of five hundred words were not at all uncommon. This, however, can only be regarded as progressive in one sense. When a cipher (in which letters and combinations of letters are assigned to characters) develops into a code system (in which complete words are substituted by code characters), it becomes much more secure, practically unbreakable. One disadvantage, however, is that both sender and addressee must own a rather thick dictionary that contains the correspondence of the numbers and the words. Security is not cheap and the price one pays is decreased user-friendliness. The message becomes more secure as the passing on of the key becomes more complicated. On the other hand, even this increased security is relative - if there is enough sample, the codebreaker may draw logical conclusions from the supposed content, the context and the relationship of the code words. And if the codebreaker happens to obtain a copy of the dictionary of the code words (either by stealing it, or in case of a historian, simply looking it up in the archives), he will have an easy job.

If he does not, his task is almost impossible. The story of The Man with the Iron Mask illustrates this well. Originally a story by Voltaire, it is elaborated 
on by Alexandre Dumas in his novel: Louis XIV in 1691 ordered a young man to be shipped in utmost security to the island of Sainte-Marguerite on the Mediterranean. The prisoner, wearing an iron mask, was looked after by the governor of the prison himself. Nobody could meet him during his life, and not even in his death in 1703. A number of theories have been formulated about the identity of this mysterious prisoner, and the source of one of these is a letter which contains the most important piece of information - the name of the prisoner - in the form of a number group serving as nomenclature. The supposedly quite extensive nomenclature dictionary was never found despite the best efforts of historian cryptologists, so the scientific debate is left open on the real name of the man with the iron mask that was concealed by this particular combination of numbers. ${ }^{33}$

33 David Kahn, "The Man with the Iron Mask: Encore et Enfin: Cryptologically," Cryptologia 29/1 (2005): 43-49; Emile Burgaud et commandant Bazeries, Le Masque de fer, révélation de la correspondance chiffrée de Louis XIV (Paris: Firmin-Didot, 1893). 
